\title{
Effect of granulocyte-colony stimulating factor on expression of selected proteins involved in regulation of apoptosis in the brain of newborn piglets after cardiopulmonary bypass and deep hypothermic circulatory arrest
}

\author{
Peter Pastuszko, MD, ${ }^{a}$ Gregory J. Schears, MD, ${ }^{\mathrm{b}}$ Afsaneh Pirzadeh, MD, ${ }^{\mathrm{c}}$ Joanna Kubin, MS, ${ }^{\mathrm{d}}$ \\ William J. Greeley, MD, ${ }^{\mathrm{c}}$ David F. Wilson, $\mathrm{PhD},{ }^{\mathrm{d}}$ and Anna Pastuszko, $\mathrm{PhD}^{\mathrm{d}}$
}

\begin{abstract}
Objective: The study objective was to investigate the effect of granulocyte-colony stimulating factor on the expression of proteins that regulate apoptosis in newborn piglet brain after cardiopulmonary bypass and deep hypothermic circulatory arrest.
\end{abstract}

\begin{abstract}
Methods: The newborn piglets were assigned to 3 groups: (1) deep hypothermic circulatory arrest (30 minutes of deep hypothermic circulatory arrest, 1 hour of low-flow cardiopulmonary bypass); (2) deep hypothermic circulatory arrest with prior injection of granulocyte-colony stimulating factor $(17 \mu \mathrm{g} / \mathrm{kg} 2$ hours before cardiopulmonary bypass); and (3) sham-operated. After 2 hours of post-bypass recovery, the frontal cortex, striatum, and hippocampus were dissected. The expression of proteins was measured by gel electrophoresis or protein arrays. Data are presented in arbitrary units. Statistical analysis was performed using 1-way analysis of variance.
\end{abstract}

\begin{abstract}
Results: In the frontal cortex, only Fas ligand expression was significantly lower in the granulocyte-colony stimulating factor group when compared with the deep hypothermic circulatory arrest group. In the hippocampus, granulocyte-colony stimulating factor increased Bcl-2 (54.3 \pm 6.4 vs $32.3 \pm 2.2, P=.001)$ and serine/ threonine-specific protein kinase $(141.4 \pm 19$ vs $95.9 \pm 21.1, P=.047)$ when compared with deep hypothermic circulatory arrest group. Caspase-3, Bax, Fas, Fas ligand, death receptor 6, and Janus protein tyrosine kinase 2 levels were unchanged. The $\mathrm{Bcl}-2 / \mathrm{Bax}$ ratio was 0.33 for deep hypothermic circulatory arrest group and 0.93 for the granulocyte-colony stimulating factor group $(P=.02)$. In the striatum, when compared with the deep hypothermic circulatory arrest group, the granulocyte-colony stimulating factor group had higher levels of Bcl-2 $(50.3 \pm 7.4$ vs $31.8 \pm 3.8, P=.01)$, serine/threonine-specific protein kinase $(132.7 \pm 12.3$ vs $14 \pm 1.34$, $\left.P=2.3 \times 10^{6}\right)$, and Janus protein tyrosine kinase $2(126 \pm 17.4$ vs $77.9 \pm 13.6, P=.011)$, and lower levels of caspase- $3(12.8 \pm 5.0$ vs $32.2 \pm 11.5, P=.033)$, Fas ( $390 \pm 31$ vs $581 \pm 74, P=.038)$, Fas ligand (20.5 \pm 11.5 vs $57.8 \pm 15.6, P=.04)$, and death receptor $6(57.4 \pm 4.4$ vs $108.8 \pm 13.4, P=.007)$. The Bcl-2/ Bax ratio was 0.25 for deep hypothermic circulatory arrest and 0.44 for the granulocyte-colony stimulating factor groups $(P=.046)$.
\end{abstract}

Conclusions: In the piglet model of hypoxic brain injury, granulocyte-colony stimulating factor decreases proapoptotic signaling, particularly in the striatum. (J Thorac Cardiovasc Surg 2012;143:1436-42)

Congenital heart disease (CHD) is the most common birth defect, affecting 8 per 1000 live births. Many of these neonates will require early surgical intervention. Today, because of improved perfusion techniques, pharmacology,

From the Department of Surgery, ${ }^{\mathrm{a}}$ University of California, San Diego, Calif; Department of Anesthesiology and Critical Care, ${ }^{b}$ Mayo Clinic, Rochester, Minn; Department of Anesthesiology and Critical Care, ${ }^{\mathrm{c}}$ Children's Hospital of Philadelphia, Philadelphia, $\mathrm{Pa}$; and Department of Biochemistry and Biophysics, ${ }^{\mathrm{d}}$ University of Pennsylvania, School of Medicine, Philadelphia, Pa.

Funding: The research was supported by Grant HL-58669 from the National Institutes of Health.

Disclosures: Authors have nothing to disclose with regard to commercial support. Received for publication Jan 14, 2011; revisions received Sept 8, 2011; accepted for publication Jan 4, 2012; available ahead of print Feb 3, 2012.

Address for reprints: Peter Pastuszko, MD, University of California San Diego, Surgery, 3030 Children's Way, Suite 202, San Diego, CA 92123 (E-mail: ppastuszko@ rchsd.org).

0022-5223/\$36.00

Copyright (C) 2012 by The American Association for Thoracic Surgery

doi:10.1016/j.jtcvs.2012.01.018 and perioperative care, even the most complex surgical repairs in this patient population are performed with low operative mortality.

Better survival in infants and children with CHD requiring surgical correction has led to a shift in focus to the longterm outcomes, particularly neurodevelopmental progress and quality of life. Recent studies have demonstrated neurodevelopmental dysfunction in patients with complex CHD. The prevalence of this impaired neurologic function seems to vary with the specific cardiac diagnosis. ${ }^{1,2}$ Long-term follow-up studies in these children have revealed distinctive patterns of neurodevelopmental dysfunction characterized by cognitive impairment, impaired executive function, expressive speech and language abnormalities, impaired visual-spatial and visual-motor skills, attention deficit/hyperactivity disorder, motor delays, and other learning disabilities. ${ }^{3,4}$ 


$$
\begin{aligned}
& \text { Abbreviations and Acronyms } \\
& \begin{aligned}
\text { CHD } & =\text { congenital heart disease } \\
\text { CPB } & =\text { cardiopulmonary bypass } \\
\text { DHCA } & =\text { deep hypothermic circulatory arrest } \\
\text { DR6 } & =\text { death receptor } 6 \\
\text { Fas-L } & =\text { Fas ligand } \\
\text { G-CSF } & =\text { granulocyte-colony stimulating factor } \\
\text { LFCPB } & =\text { low-flow cardiopulmonary bypass } \\
\text { pAkt } & =\text { serine/threonine-specific protein kinase } \\
\text { pJAK2 } & =\text { Janus protein tyrosine kinase } 2 \\
\text { SEM } & =\text { standard error of the mean } \\
\text { STAT } & =\text { signal transducer and activator of } \\
& \text { transcription }
\end{aligned}
\end{aligned}
$$

Multiple causative factors for neurodevelopmental dysfunction in patients with complex CHD have been cited. ${ }^{5}$ Patient factors have included genetic abnormalities, congenital syndromes, and in utero and postnatal abnormal cerebral blood flow patterns leading to an underdeveloped central nervous system and microcephaly. Putative surgical factors, such as deep hypothermic circulatory arrest (DHCA) and low-flow cardiopulmonary bypass (LFCPB), have been proposed. ${ }^{4}$ Early postoperative factors such as low cardiac output, hypoxemia and hyperthermia also may contribute. Genetic abnormalities and other patient factors clearly cannot be altered. However, factors related to DHCA, LFCPB execution, and early postoperative management are modifiable.

Advances in the treatment of cerebral injury associated with hypoxic/ischemic insult depend on thorough understanding of the critical neuropathologic processes involved in neuronal survival and death. Apoptosis, a programmed cell death, seems to be the primary mechanism responsible for cell death in the newborn brain. We have previously used a piglet model of cardiopulmonary bypass (CPB) to delineate the mechanisms of brain injury associated with prolonged DHCA and LFCPB. ${ }^{6}$ Marked alterations in expression of selected proteins that play well-established roles in regulation of apoptosis were observed, and we have identified strategies that can limit this neuropathology. ${ }^{7}$

The goal of the present study was to determine whether granulocyte-colony stimulating factor (G-CSF) may be an effective neuroprotective agent, as tested in our CPB/ DHCA model of hypoxic cerebral injury. G-CSF, a member of the cytokine family of growth factors, is a glycoprotein broadly present within the central nervous system. G-CSF exerts its effect via a specific receptor present on hematopoietic, neuronal, and glial cells. Numerous studies have reported that ischemia upregulates the production of G-CSF and its receptors. Exogenous administration of G-CSF has been shown to be neuroprotective in a variety of stroke models. $^{8-10}$ It has potent anti-inflammatory ${ }^{11}$ and antiexcitatory properties. ${ }^{8}$ However, its most important function may be as a strong antiapoptotic factor. ${ }^{8,12,13}$ Available studies suggest that G-CSF is capable of permeating the intact blood-brain barrier and is safe for use in humans. ${ }^{8}$

We hypothesized that proapoptotic proteins increase and antiapoptotic proteins decrease after CPB-DHCA and that pretreatment of the piglets with G-CSF can suppress these changes in signaling. To test these hypotheses, we have determined the effect of G-CSF treatment on the expression of selected regulatory proteins that play significant role in either initiation (Bax, caspase-3, Fas, Fas ligand (Fas-L), death receptor 6 [DR6]) or inhibition (Bcl-2, serine/ threonine-specific protein kinase [pAkt], and Janus protein tyrosine kinase 2 [pJAK2]) of apoptotic signaling.

\section{MATERIALS AND METHODS \\ Animal Model}

Eighteen newborn piglets, 3 to 5 days old $(2.0-3.0 \mathrm{~kg})$, were anesthetized with $4 \%$ isoflurane (Novaplus, Hospira Inc, Lake Forest, Ill). Pulse oximetry, electrocardiogram, and temperature measurements were begun immediately after induction of anesthesia. A $1.5 \%$ lidocaine- $\mathrm{HCl}$ was used as a local anesthetic. After tracheotomy, pancuronium $(1.5 \mathrm{mg} / \mathrm{kg})$ was used for neuromuscular blockade to allow mechanical ventilation. Fentanyl-citrate $(30 \mu \mathrm{g} / \mathrm{kg})$ was injected intravenously, and the animals were mechanically ventilated with a mixture of oxygen $\left(\mathrm{FIO}_{2} 21 \%\right)$ and $0.5 \%$ isoflurane. The femoral artery and vein were then cannulated, and anesthesia was maintained with $0.5 \%$ isoflurane and boluses of pancuronium $(1 \mathrm{mg} / \mathrm{kg} / \mathrm{h})$. After a 2-hour period, CPB was initiated. After bypass, the animals were recovered for 2 hours under anesthesia and then euthanized with saturated $\mathrm{KCl}$.

All animal procedures were in strict accordance with the National Institutes of Health "Guide for the Care and Use of Laboratory Animals: and have been approved by the local Animal Care and Use Committee.

\section{Cardiopulmonary Bypass Technique}

The circuit was primed with Plasma-Lyte A (Baxter Healthcare Corp, Deerfield, Ill) and 25\% albumin. Donor whole blood was then added to maintain a hematocrit of $25 \%$ to $30 \%$. Heparin (1000 units), fentanyl $(50 \mu \mathrm{g})$, pancuronium (1 mg), $\mathrm{CaCl}_{2}(500 \mathrm{mg})$, methylprednisolone (60 $\mathrm{mg}$ ), cefazolin $(100 \mathrm{mg})$, furosemide $(2 \mathrm{mg})$, and $\mathrm{NaHCO}_{3}(25 \mathrm{meq})$ were then added to the pump prime. A membrane oxygenator (Lilliput; COBE Cardiovascular, Inc, Arvada, Colo), a roller pump system (COBE), and an arterial filter (Capiox; Terumo Cardiovascular Systems, Corp, Ann Arbor, Mich) were used. A median sternotomy was performed, and after 500 units of heparin were administered intravenously, the ascending aorta and the right atrial appendage were cannulated. Full CPB flow rate was set at $150 \mathrm{~mL} / \mathrm{kg} / \mathrm{min}$. The $\mathrm{pH}$-stat blood gas management was maintained in all experiments.

After cooling to $18^{\circ} \mathrm{C}$, the piglets were introduced to 30 minutes of DHCA followed by 1 hour of LFCPB at $20 \mathrm{~mL} / \mathrm{kg} / \mathrm{min}$. All animals were then rewarmed for 30 minutes at full flow $(150 \mathrm{~mL} / \mathrm{kg} / \mathrm{min})$, separated from CPB and recovered for 120 minutes under anesthesia, and finally euthanized with saturated $\mathrm{KCl}$. The control animals did not undergo $\mathrm{CPB}$ but were anesthetized and underwent a sham operation. After euthanasia, the frontal cortex, striatum, and hippocampus were immediately dissected from the brain and frozen at $-80^{\circ} \mathrm{C}$ for later analysis.

The animals were randomly assigned to 1 of 3 groups: 1) CPB with circulatory arrest ( $\mathrm{n}=6$, DHCA group), 2) DHCA with prior injection of 


\section{Frontal Cortex}
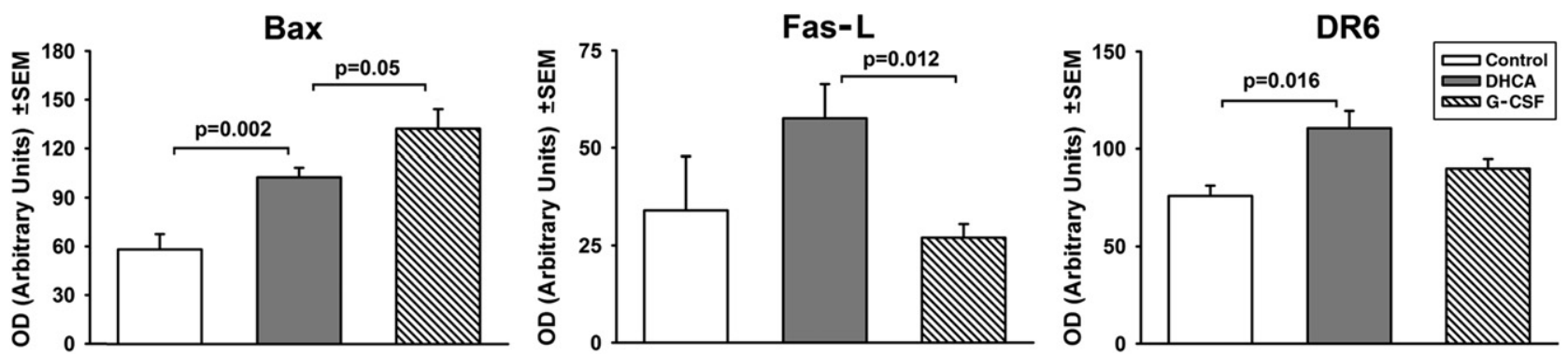

FIGURE 1. Effect of DHCA and G-CSF on Bax, Fas-L, and DR6 immunoreactivities in the frontal cortex of newborn brain. Bars represent the means \pm standard error of the mean $(S E M)$ for the density of the bands for 6 independent experiments.

G-CSF at a concentration of $17 \mu \mathrm{g} / \mathrm{kg}(\mathrm{n}=6, \mathrm{G}-\mathrm{CSF}$ group), and 3$)$ shamoperated $(n=6)$. The G-CSF was given by intravenous injection 2 hours before the beginning of bypass.

\section{Protein Expressions}

For the Western blotting, the samples of frozen tissue were homogenized, prepared, and incubated with specific antibodies as described previously. ${ }^{6,7}$ Expression of caspase-3, Fas, Fas-L, and DR6 were determined by RayBioTech, Inc (Norcross, Ga) using the protein array method.

\section{Data Analysis}

Autoradiographic films were analyzed using Scion Image software (National Institutes of Health, Bethesda, Md). Each blot contained 3 sets of samples, 2 experimental groups, and the control group. The measurements of individual proteins are presented as the means \pm standard error of the mean for 6 experiments. The data within each brain region ( 3 groups) were tested for significance by 1 -way analysis of variance, and the $P$ value for comparisons between the groups was calculated using the 2-tailed unpaired $t$ test. The Bonferroni correction for multiple comparisons would attribute significance at the $95 \%$ tile for $P$ values of .017 and marginal significance for $P$ values between .05 and .017 . Our hypotheses were tested by binary analysis of probability of observing the measured direction of the changes in protein levels with the null hypothesis of an equal probability of increase or decrease.

\section{RESULTS}

In 3 regions of the newborn piglet brain, the immunoreactivity of antiapoptotic Bcl-2, p-Akt, and p-JAK2, and proapoptotic Bax, caspase-3, Fas, Fas-L, and DR6 proteins were determined. Only the proteins that are significantly different between experimental groups are shown in Figures 1 through 4.

\section{Frontal Cortex}

Bcl-2 was not significantly different among the experimental groups of animals. Bax increased from the control value of $58.3 \pm 13.6$ to $102 \pm 8.2(P=.002)$ in the DHCA group and was significantly higher in the G-CSF group (Figure 1). The Bcl-2/Bax ratios were $0.96 \pm 0.14$ (control), $0.80 \pm 0.06$ (DHCA), and $0.58 \pm 0.09$ (G-CSF) (Table 1). pAkt, pJAK2, and Fas were not significantly different among the experimental groups. DR6 increased from control of $76 \pm 5.3$ to $110 \pm 8.9(P=.016)$ for DHCA, but there was no significant difference between DHCA and G-CSF. Fas-L slightly increased in DHCA versus control $(34 \pm 13.9$ vs $57.6 \pm 8.8)$ and decreased significantly with G-CSF versus DHCA $(57.6 \pm 8.8$ vs $27 \pm 3.5$, $P=.012)$. The caspase-3 level was too low to measure in all experimental groups.

\section{Hippocampus}

Bcl-2 was lower in the DHCA group versus control (32.3 \pm 2.16 vs $87.2 \pm 22, P=.005)$ and increased significantly in the G-CSF group (to $54.3 \pm 6.4, P=.001$ ) (Figure 2). The calculated $\mathrm{Bcl}-2 / \mathrm{Bax}$ ratios were $0.8 \pm 0.06$ (control), $0.33 \pm 0.04, P=.00001$ (DHCA), and $0.93 \pm 0.21, P=.02$ (G-SCF) (Table 1).

The pAkt was not significantly different between the control $(75 \pm 13.9)$ and DHCA $(95.9 \pm 21.1)$ groups. In the G-CSF group, pAkt increased to $141.4 \pm 19.4$ compared with both the DHCA $(P=.047)$ and control $(P=.003)$ groups (Figure 2). pJAK2, caspase-3, Fas, Fas-L, and DR6 were similar in all 3 groups.

\section{Striatum}

Bcl-2 decreased in the DHCA group compared with control $(31.8 \pm 3.8$ vs $59.9 \pm 7.2, P=.0009)$ and increased significantly in the G-CSF group compared with the DHCA group (50.3 \pm 7.4 vs $31.8 \pm 3.8, P=.01)$ (Figure 3 ). There

TABLE 1. Effect of granulocyte-colony stimulating factor on Bcl-2/ Bax ratio in the brain of newborn piglets after cardiopulmonary bypass-deep hypothermic circulatory arrest

\begin{tabular}{lccl}
\hline Region of brain & Control & DHCA & \multicolumn{1}{c}{ G-CSF } \\
\hline Frontal cortex & $0.96 \pm 0.14$ & $0.80 \pm 0.06$ & $0.58 \pm 0.09$ \\
& & & $P=.043^{*}$ \\
Hippocampus & $0.80 \pm 0.06$ & $0.33 \pm 0.04$ & $0.93 \pm 0.21$ \\
& & $P=.00001^{*}$ & $P=.02 \dagger$ \\
Striatum & $0.49 \pm 0.05$ & $0.25 \pm 0.02$ & $0.44 \pm 0.08$ \\
& & $P=.02^{*}$ & $P=.046 \dagger$ \\
\hline
\end{tabular}

Results are means \pm SEM for 6 experiments. ${ }^{*} P$ value compared with control. $\dagger P$ value compared with DHCA group. 


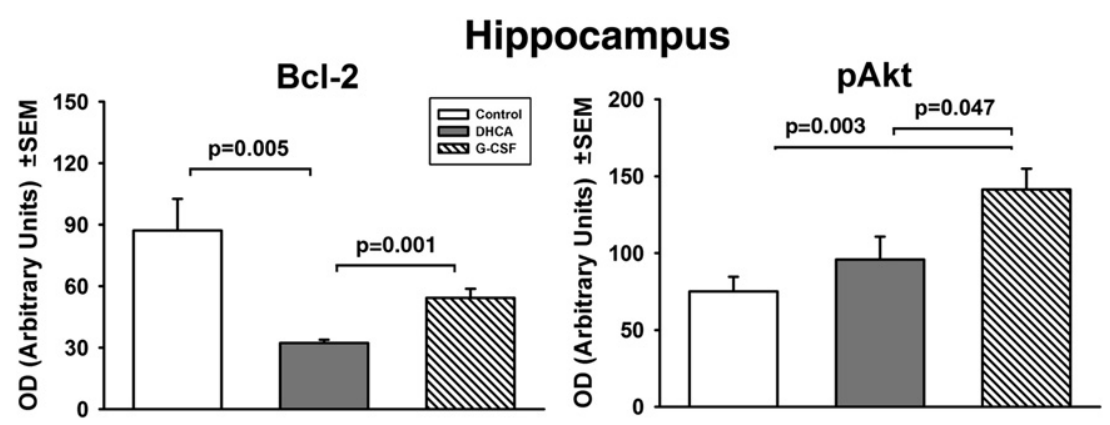

FIGURE 2. Effect of DHCA and G-CSF on Bcl-2, pAkt, and pJAK2 immunoreactivities in the hippocampus of newborn brain. Bars represent the means \pm SEM for the density of the bands for 6 independent experiments.

were no differences in Bax among the groups. The calculated $\mathrm{Bcl}-2$ to Bax ratios were $0.49 \pm 0.05$ for the control group, $0.25 \pm 0.02(P=.02)$ for the DHCA group, and $0.44 \pm 0.08(P=.046$ compared with DHCA $)$ for the G-CSF group (Table 1). pAkt was $60.4 \pm 11.5$ in the control group and decreased to $14 \pm 1.34$ in the DHCA group $(P=.0003)$. In the G-CSF group, pAkt was significantly increased (to $132.7 \pm 12.3$ ) compared with both the DHCA $\left(P=2.3 \times 10^{-6}\right)$ and control $(P=.0005)$ groups (Figure 3$)$.

The pJAK2 level was similar in the control $(75.6 \pm 17.4)$ and DHCA $(77.9 \pm 13.6)$ groups but was increased in the G-CSF group when compared with both control $(P=.015)$ and DHCA $(P=.011)$ groups (Figure 3$)$.

The caspase-3 level was low in the control group (2.4 \pm 1.7) and increased marginally in the DHCA group to $32.5 \pm$ $11.5(P=.033)$. In the G-CSF group, the mean value for caspase-3 was lower $(12.8 \pm 5.0)$ than in the DHCA group (Figure 4), but the variability was great enough that the difference was not statistically significant.

Fas level was slightly higher in DHCA $(581 \pm 74)$ than control $(425 \pm 61)$ and marginally lower than control in the G-CSF group (390 $\pm 31, P=.038)$ (Figure 4). Fas-L was $19.1 \pm 9.1$ in the control group and increased to $57.8 \pm 15.6(P=.058)$ in the DHCA group. Fas-L was marginally lower in the G-CSF group compared with the DHCA group $(20.5 \pm 11.1, P=.04)$ (Figure 4). DR6 was $61.6 \pm$ 14.8 in the control group and marginally increased to $108.8 \pm 13.4(P=.046)$ in the DHCA group and decreased in the G-CSF group $(57.4 \pm 4.4, P=.007)$ compared with the DHCA group (Figure 4).

\section{DISCUSSION}

The purpose of this study was to determine whether pretreatment with G-CSF decreases proapoptotic signaling in the newborn brain in a hypoxia/ischemia model of CPB and DHCA. To achieve this, changes in phosphorylation and expression of selected proteins in the brain of newborn piglets were measured. All investigated proteins have wellestablished roles in the regulation of apoptotic activity.

There are 2 primary reasons for focusing on apoptotic activity. First, several studies shown that apoptosis, rather than necrosis, is the predominant mechanism involved in cell death in the neonatal brain. Second, apoptotic processes are activated within hours of reperfusion, whereas necrosis can be detected only after longer recovery times.

A newborn piglet model was chosen to take advantage of the similar stage of development of the brain and similar size to the human newborn. The CPB-DHCA protocol used in our study was 30 minutes of DHCA followed by 60 minutes of low flow at $20 \mathrm{~mL} / \mathrm{kg} / \mathrm{min}$. The protocol was selected on the basis of our extensive experience with evaluating apoptotic activity associated with different circulatory arrest periods and low flow rates. The protocol was shown to result in activation of apoptotic signaling that was large enough to be easily measured and reproduced.

\section{Striatum}
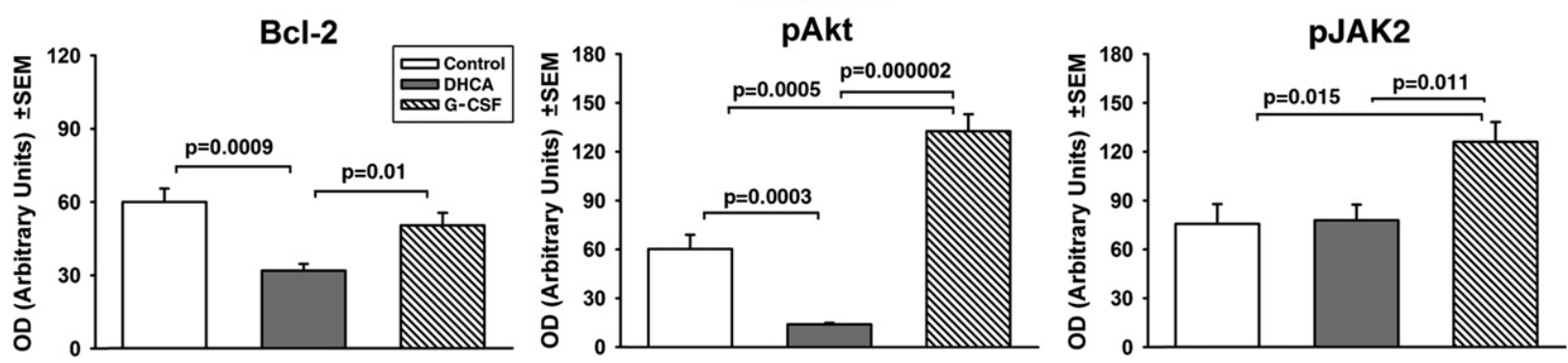

FIGURE 3. Effect of DHCA and G-CSF on Bcl-2, pAkt, and pJAK2 immunoreactivities in the striatum of newborn brain. Bars represent the means \pm SEM for the density of the bands for 6 independent experiments. 


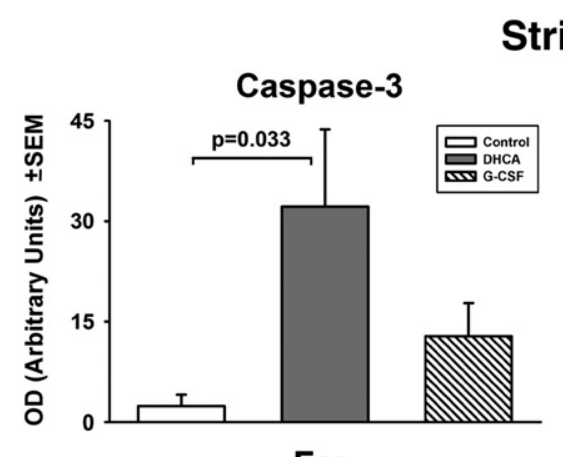

\section{Striatum}
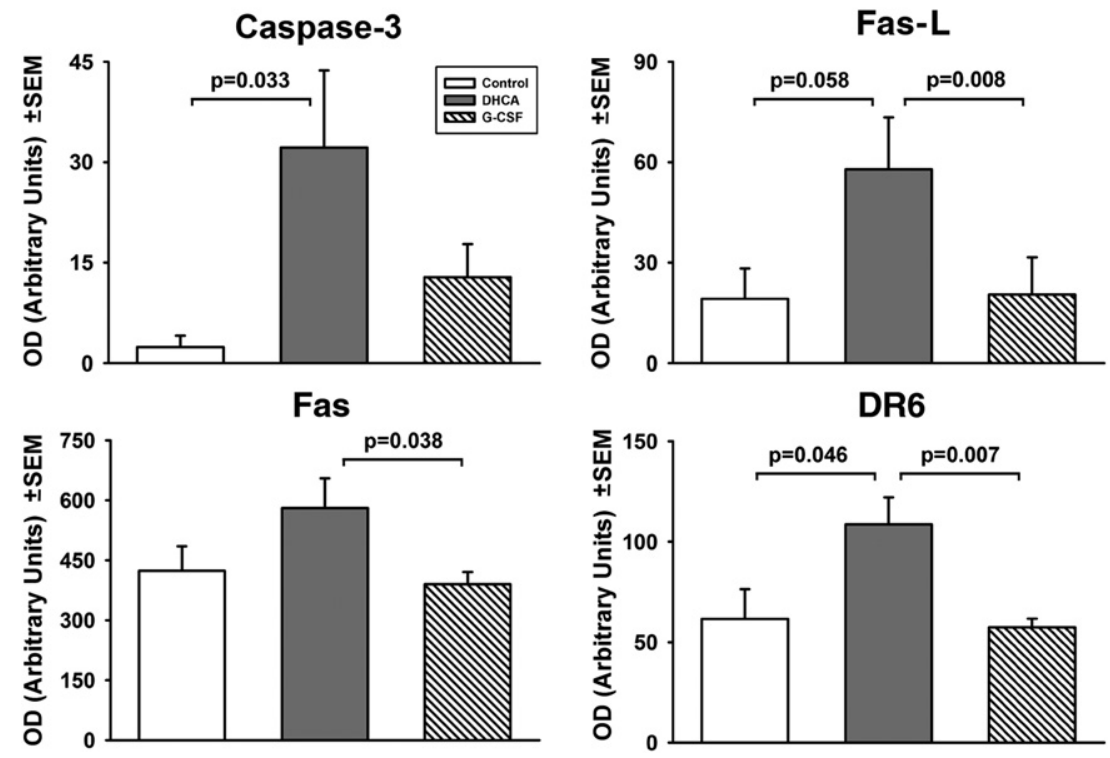

FIGURE 4. Effect of DHCA and G-CSF on caspase-3, Fas, Fas-L, and DR6 immunoreactivities in striatum of newborn brain. Bars represent the means \pm SEM for the density of the bands for 6 independent experiments.

This study demonstrates that CPB-DHCA increases proapoptotic signaling particularly in striatum of newborn piglets. The administration of G-CSF before DHCA diminishes this proapoptotic signaling and increases antiapoptotic signaling in this region of the newborn brain, as demonstrated by decreased expression of caspase-3, Fas, Fas-L, and DR6, and increased expression of $\mathrm{Bcl}-2$, pAkt, and pJAK2 proteins.

DHCA did not significantly change most of the proteins in the frontal cortex and hippocampus. Only Bax and DR6 levels were elevated in the cortex and Bcl-2 level decreased in the hippocampus. In the hippocampus, treatment with G-CSF resulted in increased expression of pAkt and Bcl-2, whereas in the frontal cortex it lead to decreased expression of Fas-L and increased expression of Bax.

Fas, Fas-L, DR6, and caspase-3 are the proapoptotic proteins. Fas is a member of the tumor necrosis factor receptor family of cell surface death receptors that mediates apoptotic signals on binding to its specific ligand, Fas-L. Ligation of Fas to Fas-L results in formation of the death-inducing signaling complex and activation of the proteolytic caspase cascade. ${ }^{14}$ Fas plays an important role in parenchymal cell apoptosis in many organs during tissue injury and inflammatory infiltration of lymphocytes.

Another member of the tumor necrosis factor receptor family that can induce apoptosis is DR6. DR6 is broadly expressed by developing neurons and is required for normal cell body death and axonal pruning both in vivo and after trophic-factor deprivation in vitro. DR6 can induce apoptosis by triggering caspases activation and degeneration of both neuronal cell bodies (via Bax and caspase-3) and axons (via caspase-6).
Caspase-3 plays a vital role in the induction, transduction, amplification, and execution of apoptotic signals within the cell. Caspase-3 is activated in different hypoxia-ischemia models, and its inhibition has been shown to have neuroprotective effects in both adult and neonatal brains. ${ }^{15}$ In the striatum, there was a significant increase of caspase-3 in the DHCA group and a clear trend toward decreased expression of this protein in the G-CSF group.

G-CSF also has an effect on Bcl-2 and Bax, 2 members of Bcl-2 family of proteins that can play a substantial role in regulating cell death by apoptosis. ${ }^{16,17}$ They can promote cell survival (Bcl-2) or cell death (Bax). Several studies have shown that Bax plays a critical role in hypoxic/ ischemic injury, and its deficiency has protective effect in hypoxic brain damage. In response to hypoxia or ischemia, Bax undergoes a conformational change and leads to activation of the caspase cascade. Bcl-2, an antiapoptotic protein of the Bcl-2 family, can prevent this conformational change in Bax. There is evidence that overexpression of $\mathrm{Bcl}-2$ protects against apoptosis and ischemic neuronal death. Bcl-2 can diminish the Fasmediated apoptosis.

The increase in expression of Bcl-2 in the striatum and hippocampus in G-CSF-treated animals in our study suggests that an important mechanism of protection by G-SCF can be through increase in the level of $\mathrm{Bcl}-2$. Increased $\mathrm{Bcl}-2$ as one protective mechanism of G-CSF was proposed also by $\mathrm{Cao}$ and colleagues. ${ }^{18}$ They examined the effect of G-CSF on dopaminergic neurons in a mouse model of Parkinson disease and reported that G-CSF significantly decreased the loss of tyrosine hydroxylase-positive neurons 
and increased the Bcl-2 level. The active form of Bcl-2 can heterodimerize with Bax, and their ratio correlates with the cellular susceptibility to apoptotic stimuli. An increased $\mathrm{Bax} / \mathrm{Bcl}-2$ ratio occurs in piglets after hypoxic insult, which is consistent with increased susceptibility to apoptosis in the hypoxic newborn brain. ${ }^{16}$

The present study shows that in both striatum and hippocampus, the Bcl-2/Bax ratios after DHCA were approximately half of those in sham-operated animals. These findings are in agreement with the report by Zhang and colleagues ${ }^{17}$ that the $\mathrm{Bax} / \mathrm{Bcl}-2$ ratio increased after $\mathrm{CPB}$ in the hippocampus in a rat model of hypothermic $\mathrm{CPB}$ with hemodilution.

Injecting G-CSF before bypass nearly completely abolished the DHCA-dependent decrease of the Bcl-2/Bax ratio in the hippocampus and striatum, consistent with a protective effect of G-CSF against apoptotic damage. This is similar to the data of Solaroglu and colleagues, ${ }^{12}$ who reported that in a rat ischemia model using middle cerebral artery occlusion, G-CSF increased Bcl-2 expression and decreased Bax translocation to mitochondria.

The antiapoptotic action of G-CSF also can occur through activation of the neuronal PI3K/Akt pathway. ${ }^{8}$ This is also one of possible mechanisms of G-CSF protection observed in our study. The pAkt levels decreased in the striatum and remained unchanged in the hippocampus after DHCA when compared with sham-operated animals. In the animals treated with G-CSF, however, pAkt increased in both brain regions compared with sham-operated or DHCA animals. Akt is an important antiapoptotic protein that helps to control the balance between cell survival and cell death via several mechanisms. For example, Bad, another proapoptotic member of the Bcl-2 family, in its unphosphorylated form can bind to Bcl-XL (antiapoptotic protein) and thus block cell survival. Activation of Akt induces Bad phosphorylation and inhibits its proapoptotic activity.

The region of the brain with the greatest increase of pAkt in response to G-CSF treatment was the striatum. This region also showed significant increase of JAK2. JAKs are able to phosphorylate the signal transducer and activator of transcription (STAT) protein family after stimulation of several different membrane receptors. In a focal cerebral ischemia rat model, STAT3 expression in the penumbra of the infarction has been shown to be increased after G-CSF treatment. ${ }^{9}$ Komine-Kobayashi and colleagues ${ }^{19}$ reported that activation of the JAK2/STAT3 pathway by G-CSF activates $\mathrm{Bcl}-2$ protein after transient focal cerebral ischemia in mice, thus decreasing apoptotic cell death.

As we have described, the evidence for a protective effect of G-CSF was particularly strong in the striatum, one of the regions of the brain that is most vulnerable to hypoxia/ischemia-induced injury. In the striatum, its protective effect was manifested by an increase of Bcl-2, Bcl-2/Bax ratio,
pAkt, and pJAK-2, and a decrease of caspase-3, Fas, Fas-L, and DR6 compared with DHCA alone. G-SCF can also protect dopaminergic neurons via other pathways. ${ }^{20}$

Several studies have shown that hypoxic/ischemic brain injury results in a characteristic pattern of damage in the striatum, with the evidence for both apoptotic and necrotic cell death detected in the brains of newborn piglets ${ }^{21}$ and immature rats. ${ }^{22}$

Striatum, caudate putamen, and nucleus accumbens regions of the brain are the most important subcortical structures in the motor circuit and the main input sites for the basal ganglia. This area has been implicated in movement control and plays a critical role in memory function. Children who underwent heart surgery with $\mathrm{CPB}$ and DHCA as neonates or infants show distinctive patterns of neurologic disturbance. Neurocognitive dysfunction after CPB impairment has been well documented. ${ }^{23}$ The incidence of cognitive dysfunction immediately after cardiac surgery is reported in the range of $20 \%$ to $80 \%$, with many patients experiencing long-term or permanent residual deficits ${ }^{24,25}$ consistent with significant long-term injury to the striatum and hippocampus.

\section{CONCLUSIONS}

In a newborn piglet $\mathrm{CPB} / \mathrm{DHCA}$ model, administration of G-CSF before DHCA decreases proapoptotic signaling activity particularly in the striatum and to a lesser degree in the hippocampus, 2 regions of the brain particularly prone to injury in hypoxic/ischemic insult. As hypothesized, in the striatum, 7 of the 8 proteins increased or decreased (5 significantly) after DHCA (DHCA compared with control) and all 8 (6 significantly) of the proteins increased or decreased in the G-CSF-treated piglets compared with those without G-CSF treatment. Our results are consistent with the hypothesis that G-CSF may be an important neuroprotective agent, leading to improve outcomes in high-risk neonates requiring surgical repair for CHD.

\section{References}

1. Shillingford AJ, Glanzman MM, Ittenbach RF, Clancy RR, Gaynor JW, Wernovsky G. Inattention, hyperactivity and school performance in a population of school age children with complex congenital heart disease. Pediatrics. 2008; 121:e759-67.

2. Gaynor JW, Gerdes M, Nord AS, Bernbaum J, Zackai E, Wernovsky G, et al. Is cardiac diagnosis a predictor of neurodevelopmental outcome after cardiac surgery in infancy? J Thorac Cardiovasc Surg. 2010;140:1230-7.

3. Tabbutt S, Nord AS, Jarvik GP, Bernbaum J, Wernovsky G, Gerdes M, et al. Neurodevelopmental outcomes after staged palliation for hypoplastic left heart syndrome. Pediatrics. 2008;121:476-83.

4. Forbess JM, Visconti KJ, Hancock-Friesen C, Howe RC, Bellinger DC, Jonas RA. Neurodevelopmental outcome after congenital heart surgery: results from an institutional registry. Circulation. 2002;106(12 Suppl. 1):I95-102.

5. Gaynor JW, Wernovsky G, Jarvik GP, Bernbaum J, Gerdes M, Zackai E, et al Patient characteristics are important determinants of neurodevelopmental outcome at one year of age after neonatal and infant cardiac surgery. J Thorac Cardiovasc Surg. 2007;133:1344-53. 
6. Pastuszko P, Liu H, Mendoza-Paredes A, Schultz SE, Markowitz SD, Greeley WJ, et al. Brain oxygen and metabolism is dependent on the rate of low-flow cardiopulmonary bypass following circulatory arrest in newborn piglets. Eur J Cardiothorac Surg. 2007;31:899-905. Epub 2007 Mar 1.

7. Markowitz S, Mendoza-Paredes A, Liu H, Pastuszko P, Schultz S, Schears G, et al. Response of brain oxygenation and metabolism to deep hypothermic circulatory arrest in newborn piglets: comparison of $\mathrm{pH}$ - and alpha-stat strategies. Ann Thorac Surg. 2007;84:170-6.

8. Schneider A, Kruger C, Steigleder T, Weber D, Pitzer C, Laage R, et al. The hematopoietic factor G-CSF is a neuronal ligand that counteracts programmed cell death and drives neurogenesis. J Clin Invest. 2005;115:2083-98.

9. Schabitz WR, Kollmar R, Schwaninger M, Juettler E, Bardutzky J, Scholzke MN, et al. Neuroprotective effect of granulocyte colony-stimulating factor after focal cerebral ischemia. Stroke. 2003;34:745-51.

10. Gibson CL, Bath PM, Murphy SP. G-CSF reduces infarct volume and improves functional outcome after transient focal cerebral ischemia in mice. J Cereb Blood Flow Metab. 2005;25:431-11.

11. Hartung T, Von Aulock S, Schneider C, Faist E. How to leverage an endogenous immune defense mechanism: the example of granulocyte colony-stimulating factor. Crit Care Med. 2003;31:S65-75.

12. Solaroglu I, Tsubokawa T, Cahill J, Zhang JH. Anti-apoptotic effect of granulocyte-colony stimulating factor after focal cerebral ischemia in the rat. Neuroscience. 2006;143:965-74.

13. Xiao BG, Lu CZ, Link H. Cell biology and clinical promise of G-CSF: immunomodulation and neuroprotection. J Cell Mol Med. 2007;11:1272-90.

14. Curtin JF, Cotter TG. Live and let die: regulatory mechanisms in Fas-mediated apoptosis. Cell Signal. 2003;15:983-92.

15. Cheng Y, Deshmukh M, D'Costa A, Demaro JA, Gidday JM, Shah A, et al. Caspase inhibitor affords neuroprotection with delayed administration in a rat model of neonatal hypoxic-ischemic brain injury. J Clin Invest. 1998;101:1992-9.
16. Ravishankar S, Ashraf QM, Fritz K, Mishra OP, Delivoria-Papadopoulos M. Expression of Bax and Bcl-2 proteins during hypoxia in cerebral cortical neuronal nuclei of newborn piglets: effect of administration of magnesium sulfate. Brain Res. 2001;901:23-9.

17. Zhang TJ, Hang J, Wen DX, Hang YN, Sieber FE. Hippocampus bcl-2 and bax expression and neuronal apoptosis after moderate hypothermic cardiopulmonary bypass in rats. Anesth Analg. 2006;102:1018-25.

18. Cao XQ, Arai H, Ren YR, Oizumi H, Zhang N, Seike S, et al. Recombinant human granulocyte colony-stimulating factor protects against MPTP-induced dopaminergic cell death in mice by altering Bcl-2/Bax expression levels. $J$ Neurochem. 2006;99:861-7.

19. Komine-Kobayashi M, Zhang N, Liu M, Tanaka R, Hara H, Osaka A, et al. Neuroprotective effect of recombinant human granulocyte colony-stimulating factor in transient focal ischemia of mice. J Cereb Blood Flow Metab. 2006;26:402-13.

20. Huang HY, Lin SZ, Kuo JS, Chen WF, Wang MJ. GCSF protects dopaminergic neurons from 6-OHDA induced toxicity via the ERK pathway. Neurobiol Aging. 2007;28:1258-69.

21. Martin LJ, Brambrink A, Koehler RC, Traystman RJ. Primary sensory and forebrain motor systems in the newborn brain are preferentially damaged by hypoxiaischemia. J Comp Neurol. 1997;377:262-85.

22. Johnston MV. Selective vulnerability in the neonatal brain. Ann Neurol. 1998;44: 155-6.

23. Borowicz L, Goldsborough M, Selenes O, McKann GM. Neuropsychological changes after cardiac surgery: a critical review. J Cardiothorac Vasc Anesth. 1996;10:105-11.

24. Newman M, Kirchner J, Phillips-Bute B, Gaver V, Grocott H, Jones RH, et al. Longitudinal assessment of neurocognitive function after coronary bypass surgery. $N$ Engl J Med. 2001;344:395-402.

25. Selnes O, Goldsborough M, Borowicz L, McKann GM. Neurobehavioural sequelae of cardiopulmonary bypass. Lancet. 1999;353:1601-9. 